\title{
INTERCULTURAL COMMUNICATIVE COMPETENCE IS ESSENTIAL FOR STUDENTS OF INTERNATIONAL BUSINESS - BUT CAN IT BE TAUGHT? THE CASE OF THIRD-YEAR BCOM STUDENTS
}

\author{
F. Southwood* \\ e-mail: fs@sun.ac.za / https://orcid.org/0000-0002-8247-2081
}

\section{M.-L. de la Marque Van Heukelum}

e-mail: marievh@sun.ac.za / https://orcid.org/0000-0002-4979-1195

*Department of General Linguistics

Stellenbosch University

Stellenbosch, South Africa

\section{ABSTRACT}

Intercultural communicative competence is essential for graduates wishing to work in the business sector. Such competence has become desirable for graduates who see themselves working in "demanding and highly-challenging international environments" (Sain, Kužnin and Roje 2017, 5556). In spite of the need for well-developed intercultural competence in the workplace, students of Economic and Business Science are rarely deliberately equipped with an understanding of what language, culture and communication entail. Against this background, we investigated if an intervention, in the form of a 28-lecture undergraduate course, can develop third-year BCom students' intercultural competence so as to prepare them to deal with the heterogeneity that they will encounter in the workplace (and elsewhere), both in multilingual and multi-cultural South Africa and abroad.

Based on eight of the skills and attributes identified by Deardorff (2004) as being markers of interculturally competent individuals (such as knowledge of self and others, respect, critical thinking skills, and an awareness of the importance of being interculturally competent), students $(n=18)$ were assessed prior to the commencement of the course and again upon completion thereof. Pre- and post-course questionnaires were analysed qualitatively and quantitatively, and data were coded according to the eight Deardorff (2004) markers of intercultural competence. Additionally, a focus group discussion $(n=5)$ was held at the end of the course. The data showed that development took place in the students' attitudes, knowledge and skills related to intercultural communicative competence. Certain markers of intercultural communicative competence, however, showed more substantial development than others, the notable marker showing such development being critical thinking skills.

The finding is that skills indicative of intercultural competence can indeed be developed by means of a curriculum in such a way that students think more critically about (i) cultural and linguistic diversity and (ii) their responsibility as future leaders to communicate optimally in diverse 
cultural settings. Deliberately including courses on intercultural communication in programmes for students (not only students in Humanities and Social Sciences) could contribute to personal and professional development of students and lead to graduates who are better prepared for a career in multicultural national and international business sectors. Likewise, the introduction of in-service training in intercultural communicative competence can be considered for those who are no longer students, thereby contributing to improved intercultural communication in the workplace.

Keywords: intercultural competence, intercultural communication, intercultural business communication

\section{GRADUATES NEED INTERCULTURAL COMPETENCE TO SUCCEED IN A GLOBAL WORLD}

Intercultural encounters are growing increasingly common in a greater range of the work settings in an increasing number of countries and world regions (Morley and Cerdin 2010, 805). Factors leading to this include the increasing pace of internationalisation in business and changing forms of globalisation (Morley and Cerdin 2010, 805). Whereas many are not clear on exactly what "globalisation" means, the general perception is that it "has something to do with the thesis that we now live in one world" (Giddens 2002, 7). However, as Ladegaard and Jenks $(2015,1)$ point out, this "one world" is not necessarily a "place of sameness and interconnectedness"; rather, the world is growing "both more global and more divided, more thoroughly connected and more intricately partitioned" (Geertz 2000,246) and is "a scramble of differences in a field of connections" (Geertz 2000, 250).

It is this world that our graduates enter upon completing their higher education and training, typically with superficial conceptualisations of what language, culture and communication entail. ${ }^{1}$ This can lead to superficial linguistic interactions and to an uncritical stance towards their treatment of spoken and written communication, and crucially towards their treatment of others. In the business and commerce sector, a superficial understanding of these constructs is, for instance, apparent in many corporate social responsibility reports, an analysis of which indicates a lack of awareness of the manner in which this purportedly neutral genre conveys ideologies (see Bernard 2015).

It is commonly accepted that all texts and discourses are built on prior texts and discourses (Bakhtin 1986; Fairclough 1992; Eisenhart and Johnstone 2008). The texts and discourses to which students of Economic and Business Science are typically exposed may prepare them for their role in a monocultural discursive community, but these texts and discourses are unlikely to foster an understanding of the practices in which the discursive communities of other cultures engage. In addition to culture-specific discursive communities, there are communities of practice within companies and institutions, and attaining (partial or full) membership of these 
communities of practice is not a given upon induction into the company or institution. Factors determining membership can include proficiency in the language spoken in the community, race, gender, political factors, ethnicity, geography and culture (Paltridge 2006, 28). As reported by Jones (2013) in a study on communities of practice in three South African companies, acquiring membership to communities of practice in a diverse workplace is complex. Yet, due to globalisation and digitalisation, business people are expected to interact across languages and cultures and form part of many communities of practice - indeed, companies are increasingly seeking employers who "quickly adjust to multiple cultures and work well in multinational teams" (Earley and Peterson 2004, 100) - hence a sensitisation towards the discursive norms of other linguistic and cultural groups will prepare the students better for the workplace.

In western, educated, industrialised, well-resourced contexts, digital communication is commonplace, also in the workplace. The human face is a rich source of information in social communication; individuals can, even after a brief look at a face, make inferences about the person's identity, gender, ethnicity, physical health, emotions, personality traits and social status (see Jack and Schyns 2015). Certain features of face-to-face communication are masked during some forms of digital communication, such as emailing. This could either aid intercultural communication or hamper it. Graduates need good digital communication skills (face-to-face and otherwise), as that is what the workplace requires of them, "also in economic sectors not traditionally related to digitisation e.g. farming, health care, vocational training and construction" (European Commission 2017). Thus, whether interested in an international career or not, graduates do not only need intercultural communication skills but also the ability to communicate effectively on digital platforms in their diverse work settings - in short, those who wish to be leaders need to develop intercultural skills and knowledge (see Carr 2012; Chuang 2013).

Furthermore, a lack of intercultural communicative competence is particularly damaging in the culturally diverse environments of South Africa. Graduates wishing to pursue a career in the South African business sector will find themselves working in culturally, racially, ethnically and linguistically diverse organisations and teams (see Joubert 2017). Thus, they should be equipped to handle the kind of challenges this diversity often brings. Apart from issues of diversity, the country's history of apartheid has thus far largely defined the economic environment (Rensburg and Botha 2014, 2). Grant (2007, 14) points out that the "White minority still act as gatekeepers for the majority group", a fact that graduates need to acknowledge and address on an often deeply personal level. Graduates need to become aware of such power and privilege imbalances, both within the workplace and outside of it, and must 
be given the tools to navigate intercultural interactions with critical insight and sensitivity.

As stated by Sain, Kužnin and Roje (2017, 55-56), "intercultural competence has clearly become one of the most desirable skills and competences for university graduates who would like to see themselves working in demanding and highly-challenging international environments". However, intercultural competence (discussed below) is rarely taught explicitly, and it is often assumed that students will acquire such competence through experience. Indeed, of the five myths regarding intercultural competence mentioned by Deardorff (2015), three are that international experience (so-called cross-cultural contact; see Bennett 2012) will automatically lead to intercultural competence, that intercultural competence is not relevant to all disciplines, and that intercultural competence somehow "comes naturally" and cannot be taught. Recent studies on higher education programmes and modules, focusing on intercultural competence, are however indicating the teachability of intercultural competence; see, e.g., Dimitrov, Dawson, Olsen and Meadows (2014) for a study amongst masters and doctoral students in Canada, and Spooner-Lane, Tangen, Mercer, Hepple and Carrington (2013) for undergraduate students of Education in Australia. Sain et al. (2017, 58) state that the impact of globalization on the world's economy has created a need for quality programmes in higher education that will offer "innovative intercultural communication curricula precisely for those who seek the knowledge that is relevant" for our globalizing world.

\section{WHAT IS INTERCULTURAL COMMUNICATIVE COMPETENCE?}

The term "intercultural competence" has several part-synonyms, such as "worldmindedness" (Sampson and Smith 1957), "multinational mindset" (Caproni, Lenway and Murtha 1992), "global centrism" (McCabe 1994), "cosmopolitanism" (Vertovec and Cohen 2002), "cultural intelligence" (Earley and Mosakowski 2004), "global understanding” (Kitsantas 2004), "global mindset" (Nummela, Saarenketo and Puumalainen 2004), and "global awareness" (Green 2012). There is not yet a commonly accepted definition of what it means to have intercultural competence, nor is there an empirically validated model of intercultural competence (Fritz et al. 2003, 2). Deardorff (2004) conducted a study on the identification and assessment of intercultural competence as a student outcome of internationalization at higher education institutions in the United States of America, and the two definitions that were deemed the best definitions of intercultural competence by administrators and researchers respectively who took part in the study were:

"Knowledge of others; knowledge of self; skills to interpret and relate; skills to discover and/or to interact; valuing others' values, beliefs, and behaviours; and relativizing one's self. Linguistic competence plays a key role" (see Deardorff 2004, 248); and 
"The ability to communicate effectively and appropriately in intercultural situations based on one's intercultural knowledge, skills and attitudes" (see Deardorff 2004, 247).

Deardorff $(2004,196)$ notes that only one definition, although not the highest rated one, was accepted by 100 per cent of the researchers, namely "the understanding of other's worldviews", which, as Deardorff $(2004,198)$ states, "substantiates other literature that views respect for other worldviews as essential to intercultural competence".

Rather than focusing on precise definitions of intercultural competence, Deardorff's (2004) study required that participating researchers and administrators define specific components that act as indicators of intercultural competence. These addressed personal attributes and an individual's comprehension and knowledge, also sometimes referred to as "knowledge and skills". Deardorff (2015) discusses these components as follows:

Personal attributes (referred to as "attitudes" by Deardorff 2015) include respect for others, i.e., showing others that they are valued, that one is interested in them, and that one is listening to them attentively. Other personal attributes indicative of intercultural competence are openness and curiosity. These three personal attributes form the foundation upon which the knowledge and skills needed for intercultural competence are built. According to Deardorff $(2015,138)$, one can create opportunities for individuals to develop these three personal attributes requisite for intercultural competence by "challenging their assumptions about their own views of the world and the ways in which they perceive others". Importantly, "[t]his challenging of assumptions can be done through the curriculum" (Deardorff 2015, 138).

Knowledge includes cultural self-awareness (which refers to an awareness of how one's culture has influenced one's identity and worldview), culture-specific knowledge, understanding the world from others' perspectives (i.e., knowledge of worldviews other than one's own), and sociolinguistic awareness (Deardorff 2015, 138).

The skills that were agreed upon as being important for intercultural competence relate to the processing of knowledge: "observing, listening, evaluating, analyzing, interpreting, and relating" (Deardorff 2015, 139). As stated by Deardorff $(2015,139)$, critical self-reflection is essential to the development and assessment of intercultural competence.

While Deardorff's (2004) study was conducted in a western, educated, industrialised, rich and democratic (WEIRD) (see Henrich, Heine and Norenzayan 2010) context (i.e., in a very different context to that of our own), we are of the opinion that the identified skills/attributes that act as markers of interculturally competent individuals are universally applicable. In this regard, it is not the specific skill or attribute that changes based on the context, but rather the degree to which that given skill or attribute is developed within the individual as a result of 
contextually determined factors. When turning to intercultural communicative competence as a subtype of intercultural competence, one should note that "intercultural communication" signals the existence of "distinct cultural or other groups in interaction with each other" (Scollon and Scollon 2001, 539). Based on Chen and Starosta (1999, 28), individuals who possess intercultural communicative competence are those who can effectively and appropriately communicate and interact with people whose culture is different to their own.

It should be noted that "culture" refers here not necessarily to something one has but to something one does. Consider the following definition of culture, by Samovar and Porter (2003, 8):

"[C]ulture is ubiquitous, multidimensional, complex, and pervasive. Because culture is so broad, there is no single definition or central theory of what it is. Definitions range from the allencompassing ('it is everything') to the narrow ('it is opera, art, and ballet'). For our purposes we define culture as the deposit of knowledge, experience, beliefs, values, attitudes, meanings, social hierarchies, religion, notions of time, roles, spatial relationships, concepts of the universe, and material objects and possessions acquired by a group of people in the course of generations through individual and group striving."

Definitions of "culture" such as that of Samovar and Porter above have been criticised, amongst others by Piller (2007, 211-213) for tying culture directly to group membership, which cannot be operationalised in empirical research. The reason for this is that the groups are too large to be real groups, in the sense that no member can know all of the other members of the group. For that reason, a "culture" is an imagined community (see Anderson 1991, 6). According to Piller $(2007,211)$, this means that "members of a culture imagine themselves and are imagined by others as group members" and therefore so-called cultural groups are to be considered discursive constructions. According to Piller $(2007,211)$, "we do not have culture but ... we construct culture discursively". We take note of Piller's objections, but work with culture as an indication of group membership (albeit membership of constructed groups), and follow Deardorff $(2015,139)$ in viewing culture as

"values, beliefs, and norms held by a group of people, which shapes how individuals communicate and behave, that is, how they interact with others. Culture does not necessarily mean only those from different national or ethnic backgrounds, but also those from other diverse groups (religious, socio-economic, gender, sexual orientation, regional) within a particular society."

\section{RESEARCH QUESTION}

The general aim of the study was to ascertain if an intervention, in the form of an intercultural 
communication course, can improve students' intercultural competency by developing attributes, knowledge and skills pertaining to aspects related to culture and intercultural communication. Against this background, we pose the following research question: Does an Intercultural Communication course develop third-year BCom students' intercultural competence and, if so, how?

\section{METHODOLOGY}

\section{Study design}

The study employed a multi-method design, making use of questionnaires and a focus group discussion. It was both quantitative (see the questionnaire) and qualitative (see the focus group discussion) in nature. The questionnaire was completed at two points (pre-course and postcourse) and thus rendered longitudinal data, whereas the focus group data was collected at only one point (post-course).

\section{Ethical considerations}

Ethical clearance was obtained from the Research Ethics Committee (Humanities) of Stellenbosch University, and institutional clearance was obtained from said university for inviting its students to participate in the study. The pre- and post-course questionnaires were both completed as part of the coursework, and as such students who were enrolled for the relevant course were all required to complete these questionnaires. All students however had to sign an informed consent form before their data could be included in the study, and it was made clear to them that such consent was voluntarily and that there would be no negative consequences should they opt not to have their data included in the study.

Students were invited by the first author (who was unknown to the students) to take part in a post-course focus group discussion led by the second author (the sole course presenter). Participation was again voluntary. Those who took part in the focus group discussion signed a non-disclosure form in addition to the general informed consent form, indicating that they endeavour not to convey the content of the discussion to any person not involved in the discussion.

We acknowledge that there is a disparity of power between the students and their lecturer, who was also the data collector. We attempted to mitigate the potential effect of this disparity on students' decision on whether or not to participate by anonymising responses completely (see below), which was also a condition on which ethical clearance was granted. We take the fact that nine students opted to not return their post-course questionnaires and 22 students opted 
to not take part in the focus group discussion as evidence that students did not feel obliged to participate.

Students were each assigned a unique questionnaire number, which they had to write on their questionnaires in order to enable pairing of their pre- and post-course responses. This number was known only to the student; in order to meet the requirements of the Research Ethics Committee, the authors deliberately did not keep a record of which student was assigned which code, and students were informed of this. Whilst this ensured complete participant anonymity, it does limit the description of the participants, because all students consented to participation, yet not all returned their post-course questionnaire, and the authors had no means of determining the identity of the non-returners.

The identity of the students participating in the focus group was known (because of the face-to-face nature of the discussion) to the second author but was not made known to the first author or to the rest of the cohort. Because of the small number of participants, we deliberately refrain from providing any potentially identifying biographical information such as ethnicity, gender or self-identified cultural grouping when reporting focus groups discussion results, apart from where this information is contained in a participant's quoted response.

\section{Participants}

Potential participants were the 2018 (and first) cohort $(\mathrm{N}=27)$ of BCom (International Business) students at Stellenbosch University, who were in the third year of the four-year programme at the time of data collection. The study took place in the first semester of the academic year; the students were to embark on a semester abroad at a partner university in the second half of that year. As stated above, the whole class was required to complete the pre- and post-course questionnaire (also see below) as part of general quality control of the course on Intercultural Business Communication, whether or not they intended to take part in the study. All 27 enrolled students were invited to take part in the study, and all 27 accepted the invitation by completing the consent form. Students were additionally invited to take part in the postcourse focus group discussion. Five ( 2 males; 3 females) accepted the invitation and attended. All 27 students completed and returned the pre-course questionnaire, but (as stated above) only 18 returned the post-course questionnaire, despite several email reminders to the cohort as a whole to return said questionnaires. As a result, not all students had a complete data set. Whilst it was possible to remove incomplete data sets from the databank, it was not possible to link any data set to any particular student. This means that it is not possible to provide the characteristic of only the 18 participating students. For this reason, although we report on the questionnaire data of 18 students, we describe the cohort of 27 as a whole below. 
The majority (19) of the cohort was South African. The foreign students were from Austria (1), France (2), Germany (2), Namibia (1), the Slovac Republic (1) and Zimbabwe (1). All selfidentified as White. There were four reported home languages: Afrikaans (10), English (13), French (2) and German (2). Students are asked at registration to indicate whether they prefer Afrikaans or English as language of teaching; all but one indicated English. The mean age of the cohort (18 females; 9 males) was 21 years 3 months (range 20 years 2 months to 25 years 2 months; median 20 years 8 months).

\section{The course}

The course ran over seven weeks, with four lecture slots per week. It was presented by the second author as a blended-learning course comprising face-to-face lectures, conveyed during one to two 50-minute sessions per week; plus computer-based self-paced tuition, groupwork in the form of group data collection and conference-style class presentations, and assessment which included an assignment requiring an ethnographic study of a local company or of the local branch of an international company. In order to simulate international collaboration contexts, in which collaborators typically infrequently have the opportunity to convene face-toface, students were required to have virtual instead of face-to-face meetings when preparing their groupwork assignment.

The teaching, learning, research and assessment activities were structured around eight themes. Themes were selected to blend together so as to make possible (i) critical and flexible application of theoretical models of intercultural business communication, but also (ii) a systematic understanding of intercultural business communication. The themes were (i) an introduction to intercultural communication; (ii) an exploration of culture, including ethnocentrism, viz. "the evaluation of other cultures according to preconceptions originating in the standards and customs of one's own culture" (English Living Oxford Dictionaries 2018); (iii) what language entails; (iv) what is meant by communication; (v) studying intercultural communication; (vi) professional communication; (vii) case studies on intercultural business communication; and (viii) an introduction to ethnographic research and ethnographic fieldwork. Each theme was accompanied by compulsory reading of seminal and recent international work in the field, and lectures included South African case studies and examples.

\section{Data collection methods}

As stated above, data were collected by means of questionnaires and a focus group discussion. At the onset of the course, all students completed a questionnaire in writing on, amongst others, what language is, what culture is and what intercultural business communication entails. This 
questionnaire (of which the structure remained the same but the examples were replaced) was re-completed at the end of the course. The questions targeted the aforementioned attributes, knowledge and skills identified by Deardorff $(2015,138-139)$. Note that many of the markers of intercultural competence identified in Deardorff's (2004) study can only be assessed in practice or in "real-world scenarios". The following markers of intercultural communicative competence were identified as those that could be evaluated in an academic setting using preand post-course assessment: (We indicate in italics what the questions on the questionnaire were that targeted each of these markers.)

(i) Knowledge of others and others' worldviews

- Identify another "cultural group" that you have contact with, describing how they differ from you.

(ii) Knowledge of self

- What is your culture?

- Describe yourself in terms of your cultural profile.

(iii) Curiosity and awareness

- Do you think it is important to know about one's colleagues' cultural background/religious disposition/gender orientation? How might this knowledge, or lack thereof, affect your work environment and relationship as co-workers? Make note of the pros and cons of knowing this kind of information.

(iv) Respect for / relatability/adaptability to others

- Imagine that you are leading an international business team. Explain the process you would go through in critiquing one of the team member's performance (which you think needs to be improved).

(v) Skills to observe and interpret

- At first glance, which of the examples below do you think constitutes an example of "intercultural communication”? Explain your answer with reference to each image. Participants were shown two images, one of a group of ethnically homogenous looking individuals, e.g. White persons dressed in what could be called Western business clothing, and the other of a group of ethnically heterogeneous looking individuals, e.g., White persons and persons of colour, the latter in so-called traditional dress.

- Carefully read the extract below and propose a possible reason (or reasons) for the incident in question:

"I'm from the USA originally, but I've lived all over the world thanks to my job. 
When I first started working with the international team, I, along with another colleague who is Japanese, was asked to pitch our latest proposal in Germany. After weeks of working on it together, we set off together to meet with our clients. In the meeting, I was up first, and so I kicked things off. After about 30 minutes of talking, I began to wonder why my colleague didn't 'jump in'. Our preparation went very well - I thought - and yet he sat there silently, listening and nodding enthusiastically. The more he nodded, the more I spoke ... at which point I began to panic, perhaps he didn't have anything to say? Did I completely misunderstand how involved he would be in this pitch? After almost 15 minutes short of two hours, I couldn't go on. I had nothing left in me and out of desperation (although he hadn't indicated that he had anything to say) asked my colleague if he had something he wished to add - to which he responded (after thanking me) that he did and pulled out an enormous lever-arch file FILLED with ideas. I was baffled."

(vi) Critical thinking skills

- Do you think that cultural differences affect us less if we are working virtually? Please explain.

- When working with people of different cultures, do you think it is preferable to ask yes-no questions or more open-ended questions?

(vii) Subject knowledge

- $\quad$ Describe what you think intercultural communication is.

- What role do you think language and culture play in intercultural communication?

(viii) Importance of developing intercultural communicative competence

- Is it necessary for someone in the business sector to study intercultural communication? Please consider this question carefully. Do not feel obliged to say "yes" merely because you are someone in the business sector and you are being compelled to take a course in intercultural communication. Please provide an explanation for your answer.

The focus group discussion was held after completion of the course. The discussion was guided by the second author and was audio-recorded. The recording was transcribed orthographically by an independent transcriber unfamiliar with the study and was checked for accuracy by a second transcriber unfamiliar with the study. Hereafter, the transcription was analysed making use of the eight Deardorff (2004) markers of intercultural competence (see (i) to (viii) above) as themes. 


\section{Data analysis}

In assessing the responses to the questionnaires, the second author used a three-point Likert scale to judge participant development in the given area. Any apparent improvement was deemed significant, and as such a three-point scale was used to most clearly illustrate this: $1=$ Little to no knowledge; 2 = Some knowledge; 3 = Firm grasp. In this regard, note that Jacoby and Matell $(1971,498)$ have shown that "regardless of the number of steps originally employed to collect the data, conversion to dichotomous or trichotomous measures does not result in any significant decrement in reliability". We illustrate how the scale was applied by indicating how a selection of answers to the question What is your culture? was rated on the Likert scale:

"White Afrikaans South African" (Rating: 1; pre-course, Participant 26).

"Anything that is familiar and acceptable for me regarding language, identity, act sequence, communication ... norms, religion" (Rating: 3; post-course, Participant 26).

"I think ... my culture is very German - yet I do have the Namibian background, which has led to me sharing a few English/Afrikaans traditions as well" (Rating: 2; pre-course, Participant 29).

"Having learnt that culture is something that is learned and adopted rather than something that is inherent, I identify with German culture, but have also adopted various habits/traditions of the English culture ..." (Rating: 3; post-course, Participant 29).

Pre- and post-course mean Likert scale scores were analysed by means of the non-parametric Wilcoxon signed-rank test.

The focus group discussion was analysed according to the same eight Deardorff (2004) markers of intercultural communicative competence. In addition, any information provided on the content, structure, delivery or other aspects of the course were noted, in order to identify potential additional themes for inclusion in the course in future years, specifically themes that in the students' opinion were topical, controversial or worthy of perusal.

\section{RESULTS}

Results from all participants were collated into group percentages for each of the eight Deardorff (2004) markers of intercultural competence. Individual participants' scores are not reported, but representative examples of individuals' responses are provided (verbatim). As can be seen from Table 1, participant scores improved for all markers over the duration of the course, with critical thinking skills increasing more than the other markers. 
Table 1: Pre- and post-course descriptive statistics for eight markers of intercultural competence

\begin{tabular}{|l|c|c|c|c|c|c|c|c|}
\hline \multirow{2}{*}{$\begin{array}{c}\text { Marker of intercultural } \\
\text { competence }\end{array}$} & \multicolumn{4}{|c|}{ Pre-course } & \multicolumn{4}{c|}{ Post-course } \\
\cline { 2 - 9 } & $\begin{array}{c}\text { Mean } \\
\text { score } \\
\text { (\%) }\end{array}$ & $\begin{array}{c}\text { Mean } \\
\text { (Likert } \\
\text { scale) }\end{array}$ & SD & SE & $\begin{array}{c}\text { Mean } \\
\text { score } \\
\text { (\%) }\end{array}$ & $\begin{array}{c}\text { Mean } \\
\text { (Likert } \\
\text { scale) }\end{array}$ & SD & SE \\
\hline $\begin{array}{l}\text { Knowledge of Others and } \\
\text { Others' Worldviews }\end{array}$ & 54 & 1.556 & 0.511 & 0.121 & 63 & 1.889 & 0.832 & 0.196 \\
\hline Knowledge of Self & 56 & 1.667 & 0.485 & 0.114 & 69 & 2.000 & 0.840 & 0.198 \\
\hline Curiosity and Awareness & 72 & 2.167 & 0.514 & 0.121 & 83 & 2.500 & 0.618 & 0.146 \\
\hline $\begin{array}{l}\text { Respect for / Relatability/ } \\
\text { Adaptability to Others }\end{array}$ & 52 & 1.556 & 0.784 & 0.185 & 85 & 2.556 & 0.705 & 0.166 \\
\hline Skills to Observe and Interpret & 55 & 1.500 & 0.618 & 0.146 & 81 & 2.111 & 0.963 & 0.227 \\
\hline Critical Thinking Skills & 59 & 5.278 & 1.364 & 0.321 & 95 & 8.444 & 0.856 & 0.202 \\
\hline Subject Knowledge & 57 & 3.444 & 0.984 & 0.232 & 81 & 4.889 & 1.023 & 0.241 \\
\hline $\begin{array}{l}\text { Importance of Developing } \\
\text { Intercultural Communicative } \\
\text { Competence }\end{array}$ & 66 & 2.000 & 0.840 & 0.198 & 93 & 2.778 & 0.548 & 0.129 \\
\hline
\end{tabular}

Note: For Deardorff (2004) markers for which there were more than one question in the questionnaire, the maximum total Likert score exceeded 3.

Table 2 indicates which of the improvements in scores from pre-course to post-course were statistically significant. As can be seen from this table, scores for all eight markers improved significantly, with the exception of Knowledge of Others and Others' Worldviews.

Table 2: Pre- course to post-course improvement for eight markers of intercultural competence

\begin{tabular}{|l|c|c|c|}
\hline \multicolumn{1}{|c|}{ Marker of intercultural competence } & Wilcoxon statistic & P & Effect size \\
\hline Knowledge of Others and Others' Worldviews & 18.000 & 0.177 & -0.789 \\
\hline Knowledge of Self & 4.500 & $0.041^{*}$ & -0.947 \\
\hline Curiosity and Awareness & 0.000 & $0.020^{*}$ & -1.000 \\
\hline Respect for / Relatability/Adaptability to Others & 0.000 & $0.003^{*}$ & -1.000 \\
\hline Skills to Observe and Interpret & 4.000 & $0.015^{*}$ & -0.953 \\
\hline Critical Thinking Skills & 0.000 & $<0.001^{*}$ & -1.000 \\
\hline Subject Knowledge & 0.000 & $<0.001^{*}$ & -1.000 \\
\hline $\begin{array}{l}\text { Importance of Developing Intercultural Communicative } \\
\text { Competence }\end{array}$ & 0.000 & $0.005^{*}$ & -1.000 \\
\hline
\end{tabular}

Note: *indicates statistical significance (with $p \leq 0.05$ taken to indicate significance). Effect size is given by the matched rank biserial correlation.

In order to illustrate what the statistical data provided above is representative of, we present at least one questionnaire and one focus group response for each of the eight Deardorff (2004) markers. An example of an improvement in the marker "Knowledge of Others and Others' Worldviews" is that of Participant 26 to the questionnaire question Identify another "cultural group" that you have contact with, describing how they differ from you:

Pre-course response: "Gypsies: not educated people who steal a lot ...” (Rating: 1)

Post-course response: “... Afrikaans culture. Differs in language they speak, body language, nonverbal communication, the use of high-context communication ..." (Rating: 3 ) 
During the focus group discussion, a participant said, "Ja, like putting the individual at the centre of it, I think is something we so infrequently do. And I think it also, I mean, just in general when you talk to people who maybe haven't, let's say, done a course like this and they, everyone is defined in these groups. It's kind of nice to have that awareness." This response was taken as indicative that the participant is aware that people and groups differ.

In terms of the marker "Knowledge of Self", Participant 14 responded as follows to the questionnaire item Describe yourself in terms of your cultural profile:

Pre-course response: “... I would say that I am both English and Afrikaans. I come from a family that does not lean towards either side, but draws heavily from both ..." (Rating: 2).

Post-course response: "I am a bicultural individual ... I associate and relate to aspects from both Afrikaans and English cultural norms" (Rating: 3).

Examples of focus group statements offered post-course are

"I can understand what my individual culture is. So it kind of gives you the tools to be able to evaluate the way you actually function compared to others and the first question ... in the first class ... about ... what is your culture ... was such a hard question for me to answer. And I understand now at the end of this course why that was such a hard question ... Because there is so many aspects to take into consideration and I realised, just me being a White Afrikaans South African guy - that is, yes, that's true - but then there are other guys in my res who are also White Afrikaans South African guys and we are completely different."

The last response indicated that the participant became aware that he is both the same as and different from other members of his constructed group.

The marker "Curiosity and Awareness" is exemplified by Participant 29's questionnaire responses below to the question Do you think it is important to know about one's colleagues' cultural background/religious disposition/gender orientation? to which a rating of 3 was assigned both pre- and post-course:

Pre-course response: "Pros: Generates mindfulness and respect for others. Can add value to business making it multicultural. Helps to understand international business partners. Cons: May create conflict ..." (Rating: 3 ).

Post-course response: "Important to generate a sense of sensitivity, which ultimately leads to a more harmonious work environment. If you are aware of culture, religious, ethnic backgrounds, you will be more likely to keep it in mind when engaging in behaviours with people part of another culture at the workplace" (Rating: 3 ).

A focus group response pertaining to this marker was "It's just, I think it's really much about 
awareness and getting to know each other - not just what the people are but more how and why the people are like that". This participant alluded to being aware that people differ and to being curious about the reasons that people are the way they are.

The marker of intercultural competence "Respect for / Relatability/Adaptability to Others" was treated in the questionnaire in the following manner by Participant 9, as answer to the scenario Imagine that you are leading an international business team. Explain the process you would go through in critiquing one of the team member's performance (which you think needs to be improved):

Pre-course response: "I would start by making it clear that I, as a leader, look at peoples' performance based on how much work they do or their attitude, irrespective of their cultural background. I would then, in an orderly manner discuss the problem ..." (Rating: 1).

Post-course response: "You have to keep in mind whether you are communicating in a high- or low-context environment. Some individuals are more relationship-based ... tell them in a personal manner, where a task-based individual ... more direct explanation" (Rating: 3 ).

During the focus group, one participant said,

"I think if you are aware that there's differences in communication styles so if you don't assume that the way I'm communicating, for example, high context as opposed to low context, if I just continue with my high context and I just think that he just needs to get what I'm saying, then there's no awareness but if I'm aware that there's low context and I'm sort of adapt to that by being more explicit in my conveying, I think that helps."

A classmate offered the following, in connection with presentation styles:

"Now ... I'll be like okay, maybe my, my choice is not the best or maybe I should just listen to what they actually have to say and how they present stuff ... but otherwise I would just, beforehand, I would just decide, no, my way's the best and the main way."

In terms of the marker "Observe and Interpret", Participant 10 chose, during the pre-course task, the image of a group of four different-looking persons (in terms of their probable ethnicity) instead of the image of two similar looking men (in terms of their dress and possible ethnicity) when instructed At first glance, which of the examples below do you think constitutes an example "intercultural communication"? Explain your answer with reference to each image, and gave a reason "As the individuals are clearly from different cultures. Image 2 depends on the cultural background of the men". Post-course, this participant answered "Both. Every individual has their particular communication style."

Two focus group responses indicating an increase in the skills of observing and interpreting were 
"Like my dad would have to speak English to his uh co-workers and neither of them were very good at it but I think that it worked so fluidly ... because I think when you know that the language barrier is there, you put extra work into paying attention to the person."

and, with reference to making presentations,

"Uh, I think it's always a bit about um not just asking but have an overview about the audience that uh listening to the presentation or will listen to the presentation."

The latter response indicates awareness that a presentation could be more effective if one makes observations about one's audience and interprets what might work best in this case.

As stated above, the marker "Critical Thinking Skills" showed the greatest improvement. Consider Participant 26's response to the question Do you think that cultural differences affect us less if we are working virtually? Please explain:

Pre-course response: "Yes, as you use different language which is more or less the same for all people" (Rating: 1).

Post-course response: "No, when communicating through email it is hard to use non-verbal communication or body language so the receiver does not know the context in which email was written ... It could seem more direct than face to face" (Rating: 3 ).

Also consider the responses of Participant 35 to the question When working with people of different cultures, do you think it is preferable to ask yes-no questions or more open-ended questions?

Pre-course response: "Yes-no questions, because everyone understands what yes/no means. Openended questions can lead to misunderstandings" (Rating: 1).

Post-course response: "I think yes-no question can lead to misunderstandings, because yes can mean different things for different people. Open ended questions will prompt people to explain their stance" (Rating: 2).

One focus group participant, reflecting on past experiences, said "Now, after the course, I think of ... some issues that came up that I, at that time, didn't really understood why it was like that ... now, after the course, I'm really a lot more aware of the reasons that stood behind that."

The marker "Knowledge of Subject" was tested by asking participants to explain what they think intercultural communication is. Participant 2 responded as follows: 
Pre-course response: "People with different cultures speak different languages which will make communication difficult" (Rating: 1).

Post-course response: "Communication between people. Communication does not only refer to language, but also context. People ref to different cultures, races, genders and ages" (Rating: 3).

During the focus group discussion, one participant said,

"If you're travelling the world and like, [you are asked] what is your culture. You answer this question at the other end of the world will be different from compared you are in your home region ... It's ... not just who is answering but also um who is questioning um about culture ... where and in which circumstances it's happening that uh you find the answer."

A classmate added

"Like I think language does have a big impact but like the non-verbal communication, those types, plays a huge role as well."

This last response indicated that the participant knows that intercultural communication pertains to more than the cultural groupings of those involved.

"Awareness of the Importance of ICC" was assessed by asking participants Is it necessary for someone in the business sector to study intercultural communication? Please consider this question carefully. Do not feel obliged to say "yes" merely because you are someone in the business sector and you are being compelled to take a course in intercultural communication. Please provide an explanation for your answer. Participant 1 answered as follows:

Pre-course response: "No/Yes. Intercultural communication is something one learns through experience. I believe something like this is helpful but not mandatory. The most important thing is to enter a new place with a respectful attitude ..." (Rating: 1).

Post-course response: "Yes because without understanding the ways different cultures communicate it is difficult to understand intentions of business partners. Can lead to more successful business deals if one understands how to be respectful to another culture" (Rating: 3).

During the focus group, the following two statements were made:

"So I think that's why miscommunication is likely to happen in a business setting or there's more likely you know, actual, small, nuanced aspect of the culture and language" and

"This is why we're in this field, and this is why we choose our degree. If we wanted to study normal business, we would have done that, but this is to equip us, this is probably one of the best courses that we have been in, that others haven't done, to equip us to engage and interact culturally beyond. I think was our specialist subject." 


\section{DISCUSSION}

Taken collectively, the quantified responses to the questionnaires, the content of the questionnaire and the focus group responses show that development took place in the students' attitudes, knowledge and skills related to intercultural communicative competence. Certain markers of intercultural communicative competence, however, showed more substantial development than others, the notable marker being critical thinking skills, which will briefly be discussed below.

In terms of intercultural communicative competence, the skill to think critically may be the most essential of all. "Critical thinking skills" is defined by Halpern $(1998,450)$ as "the deliberate use of skills and strategies that increase the probability of a desirable outcome", the desired outcome here being effective intercultural communication. Halpern $(1998,451)$ further notes that studies have shown that critical thinking can be learned in ways that promote transfer to novel contexts. Effective intercultural communication relies on the ability to communicate effectively with different people in a variety of situations, many of them being "novel contexts" that graduates will face in the workplace. Thus, the marked development in critical thinking skills, with an increase from 59 per cent to 94 per cent, could be key to the students' development of intercultural communicative competence.

Those markers for which there appeared to be less of a marked difference between preand post-course scores are aspects that rely heavily on real world experiences and maturation (e.g., knowledge of self and others). Respect, observation skills, critical thinking skills, knowledge of the subject, and the awareness of the importance of being interculturally competent can be developed well through an academic course and can be applied in practice, and these aspects can act as "tools" that can be used in real world scenarios in the future, facilitating the development of those aspects of intercultural communicative competence that require exposure, experience and maturation.

\section{CONCLUSION}

The aim of the study was to ascertain whether an intercultural communication course develops third-year BCom students' intercultural competence and, if so, how. The questionnaire and focus group data indicate that, as stated by Berardo and Deardorff (2012), intercultural competence can indeed be taught, and that some markers of intercultural competence can be improved more than others through deliberate teaching. The key finding is that seven of the eight markers of intercultural competence can be developed further by means of a university curriculum, namely student's knowledge of self, their curiosity and awareness, their respect for 
others, their observation and interpretation skills, their critical thinking skills, their subject knowledge (of which there is a need amongst South African managers, see Van den Bergh $2008,102)$, and their awareness of the importance of developing intercultural communicative competence. Furthermore, the area that showed the greatest improvement was that of the students' critical thinking skills - identified as those skills that will subsequently aid in the development of further abilities central to the development of intercultural competence. Given this finding, institutions of higher education have a responsibility to teach intercultural competence in order to prepare their graduates for the demands of the workplace.

In order to create the opportunity for students to reflect on how culture affects the way in which people do business and communicate about business, we purpose-created material that made use of various teaching and knowledge generation methods, namely face-to-face lectures, class discussions, self-paced online activities, individual and groupwork assignments, written assignments, conference-style presentations by students to their classmates, and ethnographic research. This material was intended to lead students, in an engaged manner, to a better understanding of communication within and across global businesses, at individual and corporate levels. We were interested in training students to reflect upon and think critically about the discursive practices of their own culture(s) and those of other cultures, and to view diversity as an opportunity rather than as a problem that needs fixing. From the data, it appears that we have succeeded in doing so, but follow-up testing would be needed to ascertain whether the gains could be sustained during and after their semester abroad. Also, in order to improve the course, one will need to find a way of considering the course content, presentation methods and required student engagement separately so as to establish which aspects of the course led to the greatest measure of development in the students' intercultural competence, and to suitably address those aspects of the course which require improvement.

The university at which the study was conducted strives to develop in its students the attribute of having an enquiring mind, which could be equated to Deardorff's (2015) Curiosity and Awareness, Critical Thinking Skills, Knowledge of Others and Others' Worldviews, and Knowledge of Self. Other attributes which the university strives to develop in its students are (i) becoming an engaged citizen, which relates to Deardorff's (2015) Respect for / Relatability/Adaptability to Others and Skills to Observe and Interpret, (ii) a dynamic professional, which relates to Deardorff's (2015) Subject Knowledge, and (iii) a well-rounded individual. It appears that the course in intercultural business communication has the potential to develop these attributes in the undergraduate students for which it was devised, by increasing their intercultural competence and preparing them for the contemporary international business landscape. 


\section{NOTE}

1. Our survey of the websites of 25 South African universities (including universities of technology) indicated that courses or modules in intercultural (or international) communication are offered at undergraduate and postgraduate level by at least six and five universities, respectively, and one university offers a short course focusing on intercultural communication in the workplace. These courses are typically housed in humanities faculties as opposed to the economics and/or business management faculties. As regards business communication (or corporate, professional or strategic communication), undergraduate and postgraduate courses are offered by 13 and two universities, respectively, and a short course by one. One of the universities offering business communication at undergraduate level has a BA degree in intercultural communication which includes business communication. The length, scope and focus of these offerings vary widely amongst universities, and it is possible for South African economic, commerce and business management students to graduate without enrolling for, and passing, any of these courses or modules.

\section{REFERENCES}

Anderson, Benedict. 1991. Imagined communities: Reflections on the origin and spread of nationalism. London: Verso.

Bakhtin, M. 1986. Speech genres and other late essays. Austin: University of Texas Press.

Bennett, Milton J. 2012. Turning cross-cultural contact into intercultural learning. Proceedings of the Universidad 2012 8th International Congress on Higher Education. The University for Sustainable Development, Havana, Cuba.

Berardo, Kate and Darla K. Deardorff. 2012. Building cultural competence: Innovative activities and models. Sterling, VA: Stylus.

Bernard, Taryn. 2015. A critical analysis of corporate reports that articulate corporate social responsibility. PhD diss., Stellenbosch University, South Africa.

Caproni, P., S. Lenway and T. Murtha. 1992. Multinational mindsets: Sense making capabilities as strategic resources in multinational firms. Ann Arbor, MI: Division of Research, School of Business Administration, University of Michigan.

Carr, G. 2012. Graduate students need preparation for life outside the university. The Globe and Mail, October 26, 2012. http://www.theglobeandmail.com/news/national/graduate-students-needpreparation-for-life-outside-university/article4699319/

Chen, G. M. and W. J. Starosta. 1999. A review of the concept of intercultural awareness. Human Communication 2: 27-54.

Chuang, S. F. 2013. Essential skills for leadership effectiveness in diverse workplace development. Online Journal for Workforce Education and Development 6(1). http://opensiuc.lib.siu.edu/ cgi/viewcontent.cgi?article $=1133 \&$ context $=$ ojwed

Deardorff, Darla K. 2004. The identification and assessment of intercultural competence as a student outcome of internationalization at institutions of higher education in the United States. PhD diss., North Carolina State University.

Deardorff, Darla K. 2015. A $21^{\text {st }}$ Century imperative: Integrating intercultural competence in tuning. Tuning Journal of Higher Education 3(1): 137-147. doi: 10.18543/tjhe-3(1)-2015pp137-147

Dimitrov, Nanda, Debra L. Dawson, Karyn C. Olsen and Ken N. Meadows. 2014. Developing the intercultural competence of graduate students. Canadian Journal of Higher Education 44(3): 86103. journals.sfu.ca/cjhe/index.php/cjhe/article/download/186040/185288

Earley, P. and E. Mosakowski.2004. Cultural intelligence. Harvard Business Review 82(10): 139-146.

Earley, P. C. and R. S. Peterson. 2004. The elusive cultural chameleon: Cultural intelligence as a new 
approach to intercultural training for the global manager. Academy of Management Learning \& Education 3(1):100-116.

Eisenhart, C. and B. Johnstone. 2008. Discourse analysis and rhetorical studies. In Rhetoric in detail: Discourse analyses of rhetorical talk and text, ed. B. Johnstone and C. Eisenhart, 3-21. Amsterdam, Benjamins.

English Living Oxford Dictionaries. 2018. Ethnocentric. https://en.oxforddictionaries.com/definition/ ethnocentric

European Commission. 2017. New report shows digital skills are required in all types of jobs. https://ec.europa.eu/digital-single-market/en/news/new-report-shows-digital-skills-are-requiredall-types-jobs (Accessed 8 October 2018).

Fairclough, N. 1992. Intertextuality in critical discourse analysis. Linguistics and Education 4(3-4): 269-293.

Fritz, Wolfgang, Andrea Graf, Joachim Hentze and Antje Möllenberg. 2003. A replication study of the Chen/Starosta-model of intercultural sensitivity in Germany and the USA. Working Paper Technical University Braunschweig, Institute for Marketing, 03/06. http://hdl.handle.net/ $10419 / 54829$

Geertz, C. 2000. Available light. Princeton, NJ: Princeton University Press.

Giddens, A. 2002. Runaway world: How globalization is reshaping our lives. London: Profile Books.

Green, M. 2012. Global citizenship: What are we talking about and why does it Matter? Trends and Insights for International Education Leaders. January, 2012. http://globalhighered.files. wordpress.com/2012/03/ti_global_citizen.pdf

Grant, T. 2007. Transformation challenges in the South African workplace: A conversation with Melissa Steyn of iNCUDISA. Business Communication Quarterly 70(1): 93-98.

Halpern, D. F. 1998. Teaching critical thinking for transfer across domains: Disposition, skills, structure training, and metacognitive monitoring. American Psychologist 53(4): 449-455.

Henrich, J., S. J. Heine and A. Norenzayan. 2010. The weirdest people in the world? Behavioral and Brain Science 33(2-3): 61-83. DOI: 10.1017/S0140525X0999152X.

Jack, Rachael E. and Philippe G. Schyns. 2015. The human face as a dynamic tool for social communication. Current Biology 25(14): R621-R634. https://doi.org/10.1016/j.cub.2015.05.052

Jacoby, J. and M. S. Matell. 1971. Three-Point Likert Scales are good enough. Journal of Marketing Research 8(4): 495-500.

Jones, Tamiryn. 2013. Linguistic strategies used in the construction of performance assessment discourse in the South African workplace. PhD diss., Stellenbosch University, South Africa.

Joubert, Yvonne T. 2017. Workplace diversity in South Africa: Its qualities and management. Journal of Psychology in Africa 27(4): 367-371. DOI: 10.1080/14330237.2017.1347760.

Kitsantas, A. 2004. Studying abroad: The role of college students' goals on the development of crosscultural skills and global understanding. Student Journal 38(3): 441-452.

Ladegaard, Hans J. and Christopher J. Jenks. 2015. Language and intercultural communication in the workplace: Critical approaches to theory and practice. Language and Intercultural Communication 15(1): 1-12. http://dx.doi.org/10.1080/14708477.2014.985302

McCabe, L. T. 1994. The development of a global perspective during participation in Semester at Sea. Educational Review 46(3): 275-287. https://doi.org/10.1080/0013191940460305

Morley, Michael J. and Jean-Luc Cerdin. 2010. Intercultural competence in the international business arena. Journal of Managerial Psychology 25(8): 805-809. https://doi.org/10.1108/ 02683941011089099

Nummela, M., S. Saarenketo and K. Puumalainen. 2004. A global mindset: A prerequisite for successful internationalization? Canadian Journal of Administrative Sciences 21(1): 51-64.

Paltridge, B. 2006. Discourse analysis: An introduction. London, New York: Continuum International 
Publishing Group.

Piller, I. 2007. Linguistics and intercultural communication. Language and Linguistic Compass 1(3): 208-226. doi: 10.1111/j.1749-818x.2007.00012.x

Rensburg, R. and E. Botha. 2014. Is integrated reporting the silver bullet of financial communication? A stakeholder perspective from South Africa. Public Relations Review 40(2): 144-152.

Sain, Zrinka Friganović, Milena Kužnin and Rebecca Charry Roje. 2017. Teaching intercultural competence in undergraduate business and management studies - A case study. Croatian Journal of Education 19(Sp. ed. 1): 55-71. https://doi.org/10.15516/cje.v19i0.2431

Samovar, Larry A. and Richard E. Porter. 2003. Understanding intercultural communication: An introduction and overview. In Intercultural communication: A reader, ed. Larry A. Samovar and Richard E. Porter, 6-17. Belmont, CA: Thomson Wadsworth.

Sampson, D. and H. Smith. 1957. A scale to measure world-minded attitudes. Journal of Social Psychology 45: 99-106. https://doi.org/10.1080/00224545.1957.9714290

Scollon, Ron and Suzanne Wong Scollon. 2001. Discourse and intercultural communication. In The handbook of discourse analysis, ed. Deborah Schiffrin, Deborah Tannen and Heidi E. Hamilton, 538-547. Malden, MA and Oxford, UK: Blackwell Publishers Ltd.

Spooner-Lane, Rebecca, Donna Tangen, K. Louise Mercer, Erika Hepple and Suzanne Carrington. 2013. Building intercultural competence one patch at a time. Education Research International 2013: 1-9. http://dx.doi.org/10.1155/2013/394829

Van den Bergh, R. 2008. Cultural intelligence: A comparison between managers in South Africa and The Netherlands. MA thesis, University of Pretoria, South Africa.

Vertovec, S. and R. Cohen. 2002. Conceiving cosmopolitism: Theory, context and practice. Oxford: Oxford University Press. 